\title{
BED EFFICIENCY AND VOLUMETRIC MASS TRANSFER COEFFICIENT AS MASS TRANSPORT PARAMETERS OF DISPLACEMENT PULP WASHING
}

\author{
FRANTIŠEK POTU゚ČEK \\ University of Pardubice, Faculty of Chemical Technology, Institute of Chemistry and Technology of \\ Macromolecular Materials, 53210 Pardubice, Czech Republic \\ ¿orresponding author: frantisek.potucek@upce.cz \\ Dedicated to the $70^{\text {th }}$ anniversary of the Department of Pulp and Paper, \\ "Cristofor Simionescu" Faculty of Chemical Engineering and Environmental Protection, \\ "Gheorghe Asachi" Technical University of Iasi
}

Long-fibred spruce sulphite and kraft pulps, as well as short-fibred soda pulp cooked from rapeseed straw, were subjected to displacement washing under laboratory conditions. Pure water was used as wash liquid, the conductivity of which was described by the permeability. The unmovable pulp bed was characterised by its average effective flow porosity, specific resistance, and equivalent pore diameter. The displacement washing process was divided into two periods. The first period, when spent liquor was displaced from the inter-fibre pores, was described by bed efficiency. The transport of solute in the second period, when leaching prevails, was characterised by the volumetric mass transfer coefficient. The results obtained showed that bed efficiency increases with increasing Péclet number, however, it decreases with increasing dimensionless dispersion length. The bed efficiency obtained for long-fibred spruce pulps was found to be greater compared to that for short-fibred soda rapeseed pulp. The average volumetric mass transfer coefficient determined for all the pulp types had an increasing trend with increasing superficial wash water velocity.

\section{INTRODUCTION}

Pulp washing ranks among the key unit operations in chemical pulping of wood and chemical bleaching of pulp. Industrial pulp washers use both dilution/extraction and displacement washing principles. Some washers, such as rotary vacuum and pressure drum washers $^{1}$ or belt washer, ${ }^{2}$ use one dilution/extraction stage, followed by several displacement stages, others, such as diffusion washers, are pure displacement washers with the counter-current arrangement of pulp and wash liquor streams.

The pulp mat formed on a drum's surface or travelling screen from a dilute suspension may be characterised as a porous medium ${ }^{3}$ with various local porosity and inter-fibre pore orientation. If two miscible liquids are flowing through the porous medium, then there may be some additional mixing taking place. ${ }^{4,5}$ This increased mixing caused by uneven liquid flow or by concentration gradients resulting from the liquid flow is designated dispersion. Because of the complexities of the structure of such media, it is generally too complex to describe the displacement washing mechanism by a single mathematical model. Moreover, the mass transfer by leaching must be taken into account for compressible, porous particles, such as pulp fibres. ${ }^{6,7}$

In this paper, the displacement washing of three various pulps, namely spruce sulphite and kraft pulps, and soda rapeseed pulp, was characterised by the bed efficiency for the initial period of washing, when displacement prevails, and by the volumetric mass transfer coefficient quantifying leaching of a solute from pulp fibres to wash water. Moreover, the pulp bed characteristics, such as the specific resistance, effective flow porosity, equivalent diameter of pores, as well as permeability, were described. 


\section{EXPERIMENTAL}

\section{Materials and methods}

Washing experiments were carried out using three various pulps. The sulphite spruce pulp was produced by Mondi Ybbstaler Zellstoff $\mathrm{GmbH}$ (Austria). The kraft spruce and soda rapeseed pulps were prepared under laboratory conditions. The spruce chips were obtained from Mondi Štětí (Czech Republic). Rapeseed straw, in our case, the winter hybrid genotype PR45D03, was collected from the field in Polabian lowlands, near the city of Pardubice. The pulping conditions were described in detail in our preceding papers ${ }^{8,9}$ for kraft and soda pulps, respectively. The degree of delignification expressed in terms of kappa number was determined as per Tappi Test Method T 236 om-99. Using a Kajaani FS-100 analyser, the arithmetic average length, $l_{\mathrm{A}}$, and weighted average length, $l_{\mathrm{W}}$, along with fibre coarseness, $F C$, were measured for the wet state of pulp fibres. The effective specific surface of fibres based on volume, $a_{\mathrm{V}}$, and on fibre mass, $a_{\mathrm{m}}$, for all the pulps tested was determined by the method according to Ingmanson. ${ }^{10}$ The properties of pulp fibres are given in Table 1.

Red, kraft black, and soda black liquors were obtained from Mondi Ybbstaler Zellstoff $\mathrm{GmbH}$, Mondi Štětí, and OP Olšany (Czech Republic), respectively. The density, $\rho$, dynamic viscosity, $\mu$, and surface tension, $\sigma$, of all the spent liquors (Table 2) were measured by the pycnometric method, using a capillary viscometer, and the stalagmometric method, respectively. The solids content of all spent liquors was determined according to Tappi Test Method T 211 om02. The initial lignin concentrations, $\rho_{0}$, i.e., lignosulphonates concentration of the red liquor and alkali lignin concentration of the black kraft and soda black liquors, were measured using an ultraviolet spectrophotometer Cintra 10e, at wavelengths of 260, 295, and $280 \mathrm{~nm}$, respectively. The wavelength convenient for lignosulphonates and alkali lignin absorbance measurements was determined on the basis of a wavelength scan.

Displacement washing experiments were carried out under laboratory conditions. A simplified illustration of displacement washing is shown in Figure 1. A glass washing cell with a $35 \mathrm{~mm}$ inside diameter was used. The experimental apparatus was very similar to that used by Lee. ${ }^{11}$ Pulp beds were formed from a dilute suspension of unbeaten pulp in spent liquor. After compressing to a desired thickness of $30 \mathrm{~mm}$, the consistency, i.e., mass concentration of moisture-free pulp fibres in the bed varied within the limits of 119$143,124-143$, and 79 to $92 \mathrm{~kg} \mathrm{~m}^{-3}$ for the sulphite spruce, kraft spruce, and soda rapeseed pulps, respectively. The pulp beds were not mechanically conditioned and were used as formed.

To investigate the displacement washing process, the stimulus-response method was chosen. Similarly as in previous papers, ${ }^{4-9,12}$ the wash liquid, in our case, distilled water at $25{ }^{\circ} \mathrm{C}$, was fed continuously to the top of the pulp bed through a permeable plug, approximating a step change in the concentration. The concentration of the solute to be balanced in the outlet liquor stream was monitored spectrophotometrically. The displacement washing experiments with pulp fibres, as well as the washing equipment, were described in detail in the preceding papers. ${ }^{4-9,12}$

After completing the washing run, the volumetric flow rate of the wash liquid was measured gravimetrically at the pressure drop of $7 \mathrm{kPa}$ to determine the permeability and average porosity of the pulp bed. Analogous measurements at various consistencies of the bed were focused on the determination of the effective specific surface of pulp fibres, $a_{\mathrm{V}}$ and $a_{\mathrm{m}}$, according to Ingmanson. ${ }^{10}$ The procedure for evaluating the effective specific surface has been described in detail earlier. ${ }^{13}$

Table 1

Fibre length, coarseness, and specific surface for sulphite, kraft and soda pulps

\begin{tabular}{lcccccc}
\hline Pulp & $\begin{array}{c}\text { Kappa } \\
\text { no. }\end{array}$ & $\begin{array}{c}l_{\mathrm{W}}, \\
\mathrm{mm}\end{array}$ & $\begin{array}{c}l_{\mathrm{A}}, \\
\mathrm{mm}\end{array}$ & $\begin{array}{c}F C, \\
\mathrm{mg} \mathrm{m}^{-1}\end{array}$ & $\begin{array}{c}a_{\mathrm{V}} \times 10^{-5}, \\
\mathrm{~m}^{-1}\end{array}$ & $\begin{array}{c}a_{\mathrm{m}}, \\
\mathrm{m}^{2} \mathrm{~kg}^{-1}\end{array}$ \\
\hline Sulphite & 12.5 & 2.46 & 1.24 & 0.279 & 2.08 & 675 \\
Kraft & 19.6 & 2.76 & 1.94 & 0.126 & 1.84 & 639 \\
Soda & 39.4 & 1.02 & 0.44 & 0.139 & 2.73 & 1425 \\
\hline
\end{tabular}

Table 2

Intrinsic properties (density, $\rho$, dynamic viscosity, $\mu$, and surface tension, $\sigma$ ) at $25{ }^{\circ} \mathrm{C}$, solids content, and lignin concentration, $\rho_{0}$, for red, kraft black, and soda black liquors

\begin{tabular}{lcccccc}
\hline $\begin{array}{l}\text { Spent } \\
\text { liquor }\end{array}$ & $\mathrm{pH}$ & $\begin{array}{c}\rho, \\
\mathrm{kg} \mathrm{m}^{-3}\end{array}$ & $\begin{array}{c}\mu, \\
\mathrm{mPa} \mathrm{s}\end{array}$ & $\begin{array}{c}\sigma, \\
\mathrm{mN} \mathrm{m}^{-1}\end{array}$ & $\begin{array}{c}\text { Solids } \\
\text { mass, \% }\end{array}$ & $\begin{array}{c}\rho_{0}, \\
\mathrm{~kg} \mathrm{~m}^{-3}\end{array}$ \\
\hline Red & 2.2 & 1059 & 1.30 & 55.64 & 13.6 & 76.7 \\
Kraft & 12.6 & 1096 & 1.79 & 39.95 & 20.6 & 56.0 \\
Soda & 9.2 & 1061 & 1.31 & 54.73 & 11.3 & 28.0 \\
\hline
\end{tabular}




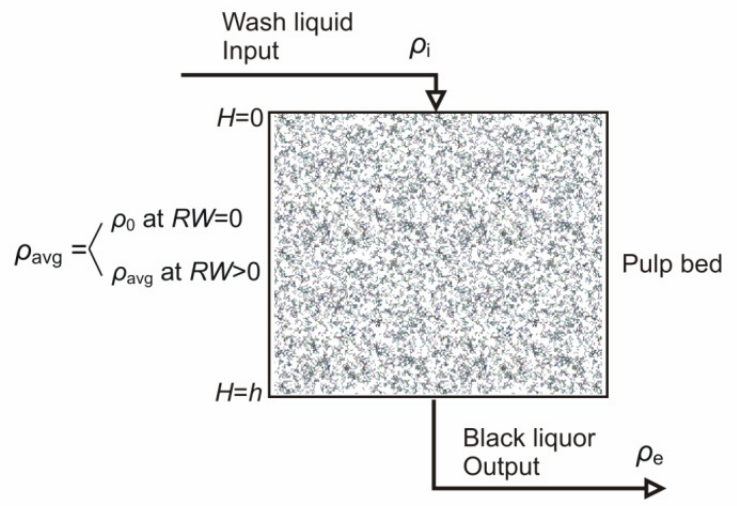

Figure 1: Semi-batch displacement washing

\section{Treatment of experimental data}

\section{Pulp fibre bed characteristics}

Generally, the superficial velocity of the wash liquid, $u$, flowing through a porous medium, directly proportional to the driving force, pressure difference, $\Delta P$, and indirectly proportional of the hydraulic resistance, $R$, may be expressed by Darcy's law in the form:

$u=B \frac{\Delta P}{\mu h}$

which holds in the laminar flow regime. ${ }^{14}$ Then, the hydraulic resistance of the pulp bed to the flow of the liquid is expressed as:

$$
R=\frac{\mu h}{B}
$$

where $\mu$ is the liquid viscosity, $h$ is the bed thickness, and $B$ is the average permeability, which expresses a measure of the liquid conductivity through the porous bed.

For laminar flow at the Reynolds number up to about 1.0 , the relation of permeability to porosity can be expressed using the well-known classical macroscopic Kozeny-Carman equation: ${ }^{13,15}$

$$
B=\frac{\varepsilon^{3}}{(1-\varepsilon)^{2} a_{\mathrm{V}}^{2} K}
$$

where $\varepsilon$ is the average effective bed porosity defined as the ratio of the volume of the pore space open to flow to the volume of the porous pulp bed, ${ }^{16}$ and $a_{\mathrm{V}}$ is the specific surface of fibres. The Kozeny constant, $K$, depending only upon the shape of pores and the ratio of the tortuous length that liquid traverses in passing through the bed to the actual bed thickness has an average value of 5.55 for randomly packed fibre beds. ${ }^{10,16}$

If the mass of fibres in the bed $m_{\mathrm{F}}=h A \rho_{\mathrm{F}}$, where $A$ is the cross-sectional area and $\rho_{\mathrm{F}}$ is the consistency of pulp, then the average specific bed resistance, $\alpha=\left(B \rho_{\mathrm{F}}\right)^{-1}$, $\left(\right.$ ref. $\left.^{17}\right)$ may be written as: $\alpha=\frac{(1-\varepsilon)^{2} a_{\mathrm{V}}^{2} K}{\varepsilon^{3} \rho_{\mathrm{F}}}$

The average specific bed resistance is a measure of the resistance offered by the fibre bed to the flow of wash liquid.

If the Kozeny-Carman equation is applicable for the flow through a porous bed, ${ }^{18}$ the equivalent pore diameter:

$d_{\text {eq }}=8.2 \sqrt{\frac{u \mu h}{\varepsilon \Delta P}}$

can be calculated in the streamline flow regime, knowing the superficial wash liquid velocity, $u$, and the pressure drop across the pulp bed, $\Delta P$.

\section{Displacement and leaching mechanisms}

In semi-batch washing of pulp (Fig. 1), when a wash liquid flows through an unmovable pulp bed, vertical variation of the solute concentration in the pulp bed arises. The solute concentration varies because of simultaneous displacement of more concentrated liquor by the wash liquid from the pores inside the bed and diffusion of the solute from the more concentrated liquor associated with the pulp fibres. The displacement occurs in the inter-fibre voids, i.e., in the volume of the bed, which is proportional to the effective flow porosity, $\varepsilon$. On the other hand, the leaching of a solute from the pulp fibres becomes in a part of the bed proportional to $1-\varepsilon$.

Hence, the total mass transfer of the solute to be balanced is given by a displacement of liquor and at the same time by leaching of a solute from fibre walls. Assuming a linear concentration gradient, i.e., $\mathrm{d} \rho / \mathrm{d} H=$ $\left(\rho-\rho_{\mathrm{i}}\right) / h$, where $\rho-\rho_{\mathrm{i}}$ is the overall change of solute concentration over the thickness of the bed, $h$ ( $c f$. Fig. 1), the total mass transfer in the unit volume of the pulp bed (in $\mathrm{kg} \mathrm{s}^{-1} \mathrm{~m}^{-3}$ ) may be described by the following equation: ${ }^{19}$

$u \frac{\mathrm{d} \rho}{\mathrm{d} H}=\frac{u}{h}\left(\rho-\rho_{\mathrm{i}}\right)+k_{\mathrm{L}} a\left(\rho_{\mathrm{avg}}-\rho_{\mathrm{i}}\right)_{\mathrm{m}}$ 
where $u$ is the superficial wash liquid velocity (in $\mathrm{m} \mathrm{s}^{-1}$ ) given as the volumetric flow rate of wash liquid per unit cross-sectional area of the bed, $\rho$ is the solute concentration within the bed (in $\mathrm{kg} \mathrm{m}^{-3}$ ), depending on the vertical coordinate, $H$, at a given time, $k_{\mathrm{L}} a$ is the average volumetric mass transfer coefficient (in $\mathrm{s}^{-1}$ ), and $\rho_{\mathrm{i}}$ and $\rho_{\text {avg }}$ are the solute concentration in the wash liquid and the average solute concentration within the bed (in $\mathrm{kg} \mathrm{m}^{-3}$ ), respectively.

The average concentration within the bed, decreasing with increasing the wash liquor ratio, may be expressed as:

$$
\rho_{\text {avg }}=\frac{\int_{R W=0}^{R W \rightarrow \infty} \frac{\rho_{\mathrm{e}}}{\rho_{0}} \mathrm{~d}(R W)-\int_{R W=0}^{R W=R W} \frac{\rho_{\mathrm{e}}}{\rho_{0}} \mathrm{~d}(R W)}{\int_{R W=0}^{R W \rightarrow \infty} \frac{\rho_{\mathrm{e}}}{\rho_{0}} \mathrm{~d}(R W)}
$$

where $\rho_{\mathrm{e}}$ is the solute concentration in the outlet stream, $\rho_{0}$ is the initial solute concentration in the bed at the start of washing, and $R W$ is the wash liquor ratio directly proportional to time and defined as the ratio of the amount of wash liquid passed through the bed and the initial amount of spent liquor present in the bed.

Equation (6) was derived on the basis of the application of the mathematical principle of superposition by Cullinan. ${ }^{19}$ The first term on the righthand side of Equation (6) expresses the mass transfer by displacement. Theoretically, for the plug flow of the wash liquid, when the spent liquor is only in the interparticle pores, the original spent liquor could be removed with the same volume of wash liquid. In practice, due to structural anisotropies, the flow of wash liquid is different from the perfect plug flow, and moreover, leaching of the substances occurs from the walls of the pulp fibres. The efficiency of displacement may be expressed by the following relationship ( $c f$. Fig. 1):

$$
E=\frac{\rho_{\mathrm{e}}-\rho_{\mathrm{i}}}{\rho_{\mathrm{avg}}-\rho_{\mathrm{i}}}
$$

which is similar to the Murphree efficiency, often used for distillation trays. ${ }^{18}$

For the wash liquor ratio equal to unity, when the washing process is governed by the displacement mechanism, the washing efficiency may be described by the bed efficiency ${ }^{19}$ expressed as:

$$
E_{\mathrm{RW}=1}=-\ln \left(1-W Y_{\mathrm{RW}=1}\right)
$$

where the regular wash yield, $W Y_{\mathrm{RW}=1}$, is defined as:

$$
W Y_{\mathrm{RW}=1}=\frac{\int_{R W=0}^{R W=1} \frac{\rho_{\mathrm{e}}}{\rho_{0}} \mathrm{~d}(R W)}{\int_{R W=0}^{R W} \frac{\rho_{\mathrm{e}}}{\rho_{0}} \mathrm{~d}(R W)}
$$

As mentioned earlier, ${ }^{8,12}$ Equation (9) may be used when the liquor volume associated in the pulp bed has a constant value during the washing process, when the displacement ratio is equal to the wash yield defined by Equation (10) and the solute concentration in the wash liquid is equal to zero.

The second term on the right-hand side of Equation (6) describes the mass transfer by leaching as:

$$
\left(u \frac{d \rho}{d H}\right)_{\text {lea }}=k_{\mathrm{L}} a\left(\rho_{\mathrm{avg}}-\rho_{\mathrm{i}}\right)_{\mathrm{m}}
$$

Knowing the time dependence of the outlet wash liquor concentration, $\rho_{\mathrm{e}}$, as a response to the step input signal, the diffusion mass transfer by leaching of a solute from pulp fibres at the wash liquor ratio greater than $R W_{\varepsilon}$ is given as follows:

$$
\left(u \frac{\mathrm{d} \rho}{\mathrm{d} H}\right)_{\text {lea }}=\left(t_{\infty}-t_{\varepsilon}\right)^{-1} \int_{R W=R W_{\varepsilon}}^{R W \rightarrow \infty} \rho_{\mathrm{e}} \mathrm{d}(R W)
$$

where $t_{\infty}$ is the total time of washing process, and $t_{\varepsilon}$ is the time when $R W=R W_{\varepsilon}$ defined as follows:

$$
R W_{\varepsilon}=\frac{A h \varepsilon \rho_{\mathrm{WL}}}{L_{0}}
$$

i.e., the ratio of the wash liquid mass in the void volume of the bed to the mass of liquor initially present in the bed. In Equation (13), $A$ is the crosssectional area of the pulp bed, $\rho_{\mathrm{WL}}$ is the density of the wash liquid, and $L_{0}$ is the initial mass of liquor present in the pulp bed.

If the solute concentration of the wash liquid $\rho_{\mathrm{i}}=0$, the mean driving force on the right-hand side of Equation (11) may be expressed as follows:

$$
\left(\rho_{\text {avg }}-\rho_{\mathrm{i}}\right)_{\mathrm{m}}=\left(R W_{\infty}-R W_{\varepsilon}\right)^{-1} \int_{R W=R W_{\varepsilon}}^{R W \rightarrow \infty} \rho_{\text {avg }} \mathrm{d}(R W)
$$

Hence, using Equations (12) and (14), an average volumetric mass transfer coefficient, $k_{\mathrm{L}} a$, can be estimated from Equation (11). The volumetric mass transfer coefficient, $k_{\mathrm{L}} a$, represents the product of mass transfer coefficient, $k_{\mathrm{L}}$, and the interfacial area, $a$, available for mass transfer in the unit volume of the pulp bed. In systems such as an unmovable pulp fibre bed, the interfacial area is not easily measured or estimated. However, the term consisting of the product - mass transfer coefficient and interfacial area - is more readily determined. Furthermore, it is convenient to use the interfacial area per unit volume, $a$, rather than the total area because the rate of mass transfer is expressed per unit volume of pulp bed.

Similarly to the height of the packed bed of an absorber, the thickness of the pulp bed, $h$, may be interpreted as the product of the height of a transfer unit, $H T U$, and the number of transfer units, $N T U .^{18}$ The height of a transfer unit, $H T U$, can be estimated as follows:

$$
H T U=\frac{u}{k_{\mathrm{L}} a}
$$

and can be defined as the height of pulp bed required to accomplish a change in concentration equal to the average driving force in this section. Thus, the height of a transfer unit and number of transfer units can be used for characterisation of the separation 
effectiveness of pulp washing in the region where the leaching becomes a dominant mechanism $\left(R W>R W_{\varepsilon}\right)$.

\section{RESULTS AND DISCUSSION Pulp bed characteristics}

The pulp fibre bed is a typical porous medium with a labyrinth of inter-fibre pores. The total pore space includes everything that is not pulp fibre, including water, which is chemically bound or otherwise immobilised. ${ }^{16}$ However, some pores, such as fibre lumens and micropores in the fibre wall, cannot be filled by the wash liquid, owing to their too strong hydraulic resistance. A random geometrical arrangement of fibres may lead to dead-end pores that are open only at one end, as well as to spatial distribution of permeability due to various local porosities. Local heterogeneities in porosity and permeability result in channelling the wash liquid inside the pulp bed. ${ }^{3,20}$ Thus, the ratio of the volume of the pore space open to flow to the volume of the porous medium itself, so-called effective flow porosity, can be determined experimentally. ${ }^{10,13}$

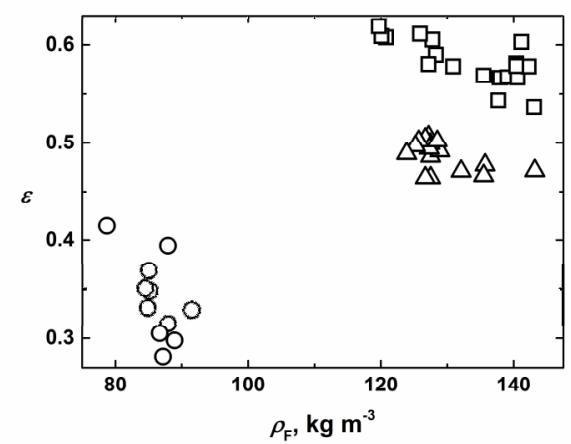

Figure 2: Effective porosity of pulp bed as a function of pulp consistency; pulps: $\square$ sulphite, $\triangle$ kraft, $\bigcirc$

soda

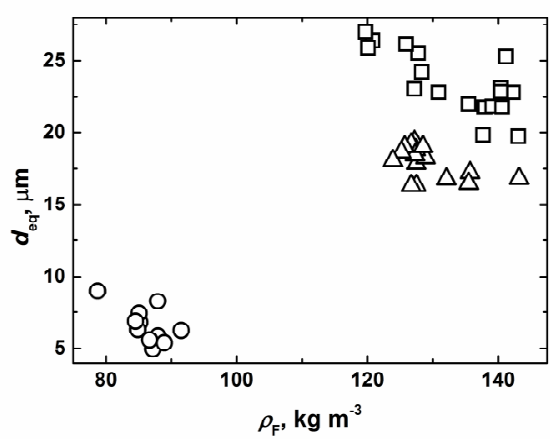

Figure 4: Equivalent pore diameter of pulp bed as a function of pulp consistency; pulps: $\square$ sulphite, $\triangle$ kraft, $\bigcirc$ soda
The effective flow porosity for sulphite, kraft, and soda pulps is illustrated in Figure 2, which clearly shows the differences among the pulp types. Also, a decrease in porosity with increasing the pulp bed consistency is obvious, mainly for the sulphite pulp. Comparing the long-fibred and short-fibred pulps, a relatively greater difference in average porosity within the limits of 0.28 to 0.42 was obtained at low pulp consistencies of 79 to $92 \mathrm{~kg} \mathrm{~m}^{-3}$ for the short-fibred soda pulp produced from rapeseed straw. The results of permeability obtained for the three various pulps through which wash water at $25{ }^{\circ} \mathrm{C}$ ( $c f$. Fig. 3) flowed correspond to those for average effective flow porosity and show that the greater the average flow porosity of the pulp bed, the greater the permeability. At the same time, the results obtained for all the pulps tested showed that they were influenced by the polydispersed character of the fibres differing in length. The different geometric configuration of the fibres in the bed then resulted in a relatively large dispersion of the measured data.

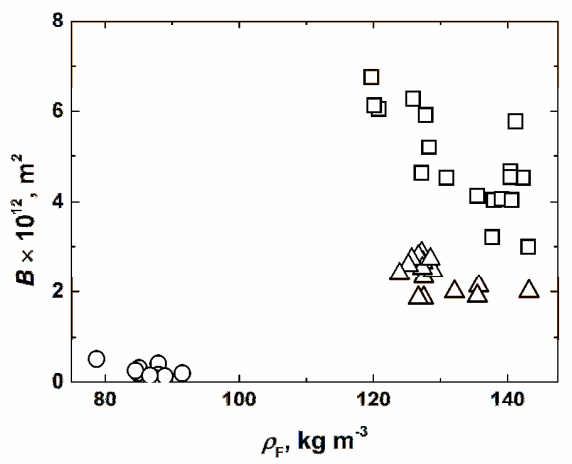

Figure 3: Permeability as a function of pulp consistency; pulps: $\square$ sulphite, $\triangle$ kraft, $\bigcirc$ soda

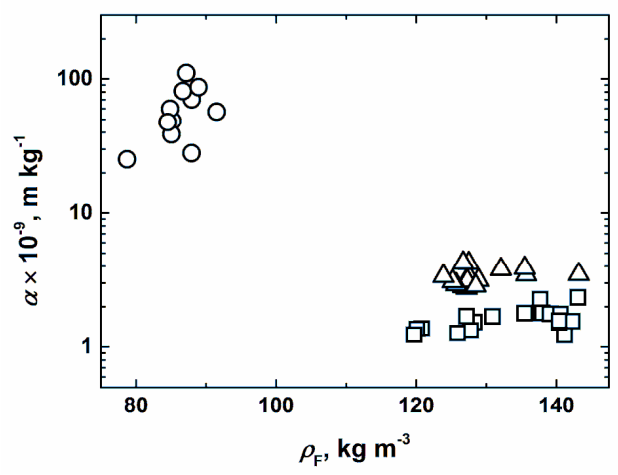

Figure 5: Specific resistance of pulp bed as a function of pulp consistency; pulps: $\square$ sulphite, $\triangle$ kraft, $\bigcirc$ soda 
The different porosity of the pulp bed had an impact on the equivalent pore diameter shown in Figure 4. For long-fibred spruce sulphite and kraft pulps, the equivalent pore diameter varied from 20 to $27 \mu \mathrm{m}$ and from 16 to $19 \mu \mathrm{m}$, respectively, while the values ranging from 5 to $9 \mu \mathrm{m}$ were found for short-fibred soda rapeseed pulp although the consistency of long-fibred pulps was much greater, $119-143 \mathrm{~kg} \mathrm{~m}^{-3}$, comparing to that of soda rapeseed pulp. It is worth mentioning that the equivalent pore diameter for the spruce pulp bed is of the same order of magnitude as the width of most coniferous and deciduous wood fibres. $^{21}$

The average specific resistance of a pulp bed should result from the bed porosity, specific surface of fibres (Table 1), and bed consistency. As it is obvious from Figure 5, the short-fibred soda rapeseed pulp revealed the greatest specific resistance, in comparison with the long-fibred spruce pulps.

\section{Washing efficiency}

Since the displacement washing process consists of two mechanisms, displacement and leaching, the whole separation process can be divided into two periods. The initial period within the limits of $R W=0$ to $R W=1$, when displacement prevails and the spent liquor is mechanically displaced by the wash liquid from inter-fibre pores, is described by the bed efficiency defined by Equation (9). As soon as the spent liquor in the inter-fibre pores is replaced by the wash liquid or week liquor and a driving force exists, the leaching of solutes from the fibre walls begins. This second period, when leaching dominates, begins at $R W=R W_{\varepsilon}$ defined by Equation (13), and may be described by the average volumetric mass transfer coefficient $k_{\mathrm{L}} a$ defined by Equation (11), characterising the rate of the transfer of solute by the leaching process.

As reported earlier, ${ }^{8,12}$ the bed efficiency at $R W=1$ depends on the heterogeneity of a porous pulp bed and increases with increasing Péclet number, $P e$, based on the bed thickness, $h$, and defined as:

$P e=\frac{h u}{D \varepsilon}$

where $u$ is the superficial wash liquid velocity, $D$ is the axial dispersion coefficient, and $\varepsilon$ is the average bed porosity. The dimensionless Péclet number can be derived from the mass balance of the tracer for a given system in unsteady state and evaluated on the basis of washing breakthrough curve. $^{12,22}$

For three types of pulp tested in this work, the dependence of the bed efficiency at $R W=1$ versus the Péclet number is shown in Figure 6. It is obvious that the bed efficiency of the sulphite pulp is slightly higher than that of the kraft pulp in the Péclet number range from 7 to 21 . The short-fibred soda rapeseed pulp brings significantly lower bed efficiency in the Péclet number range from 3 to 11 , in contrast to the long-fibred spruce pulps having lower bed resistance due to higher average flow porosity. In spite of these facts, bed efficiencies greater than unity were found for all types of pulp.

On the basis of all the data obtained for all the pulps investigated in this paper, the following correlation equation was derived:

$E_{\mathrm{RW}=1}=0.772 P e^{0.330}$

The suitability of Equation (17) was judged on the basis of the mean relative deviation of $4.1 \%$. Since the values of the regression coefficients represent an estimate of the real values, the $95 \%$ confidence intervals were also calculated, for the coefficient $(0.760 ; 0.784)$ and for the power at the Péclet number $(0.323 ; 0.337)$. It can be noted that the bed efficiency obtained for the kraft spruce pulp with the kappa number of 19.6 is similar to that previously ${ }^{8}$ found for the spruce pulp with the kappa number of 32.3 , with the bed efficiency ranging from 1.45 to 1.87 .

Figure 7 shows the dependence of the bed efficiency upon the dimensionless dispersion length $^{23}$ ranging from 75 to 773 , which confirmed that the pulp fibre beds rank with dispersive media. Comparing the short-fibred soda rapeseed pulp with the long-fibred spruce kraft and sulphite pulps, it is evident that relatively high values of the dispersion length within the limits from 177 to 773 were achieved primarily for the former. To quantify a measure of dispersion in the pulp bed, the quantitative evaluation of the effect of the dimensionless dispersion length, $L_{\mathrm{D}}$, defined as:

$L_{\mathrm{D}}=\frac{h a_{\mathrm{V}}}{4 P e}$

on the bed efficiency at $R W=1$ was derived in the form:

$E_{\mathrm{RW}=1}=6.64 L_{\mathrm{D}}^{-0.275}$

with the mean relative deviation of $3.5 \%$. The 95\% confidence intervals for the coefficient and 
power at the dispersion length were $(6.50 ; 6.79)$ and $(-0.279 ;-0.270)$, respectively. It may be noted that, although the pulps tested differ in kappa number, the correlation equation (19) corresponds very satisfactorily to that obtained for kraft spruce and hardwood pulps in a previous paper. $^{8}$

\section{Leaching}

If the concentration of the solute, in our case, alkali lignin and/or lignosulphonates, inside the fibre walls is greater than that in the liquor surrounding the fibres, i.e., the concentration

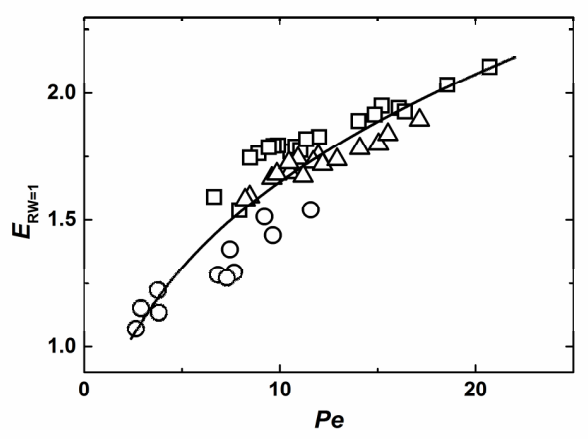

Figure 6: Dependence of bed efficiency at $R W=1$ on Péclet number for sulphite $(\square), \operatorname{kraft}(\triangle)$, and soda (○) pulps; solid line: Eq. (17) driving force exists, the transfer of the solute from fibre walls to the liquor inside inter-fibre voids takes place by leaching. The intensity of the solute transport by leaching can be expressed by the average volumetric mass transfer coefficient, $k_{\mathrm{L}} a$.

The values of the average volumetric mass transfer coefficient were plotted against the wash water superficial velocity in Figure 8. It shows that the volumetric mass transfer coefficient increased with increasing the wash water velocity, but does not differ significantly for various types of pulp.

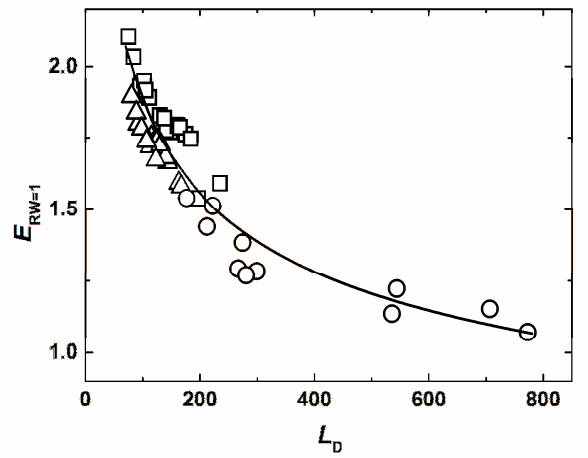

Figure 7: Dependence of bed efficiency at $R W=1$ on dimensionless dispersion length for sulphite $(\square)$, kraft $(\triangle)$, and soda $(\bigcirc)$ pulps; solid line: Eq. (19)

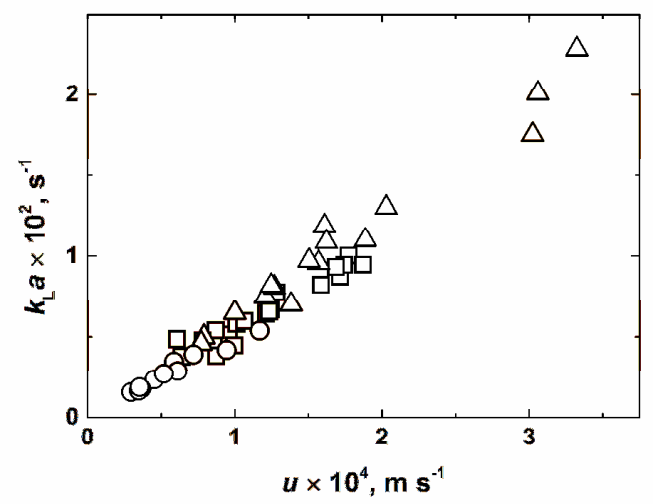

Figure 8: Dependence of average volumetric mass transfer coefficient on superficial wash liquid velocity for sulphite $(\square)$, kraft $(\triangle)$, and soda $(\bigcirc)$ pulps

The values of the average volumetric mass transfer coefficient were plotted against the wash water superficial velocity in Figure 8. It shows that the volumetric mass transfer coefficient increased with increasing the wash water velocity, but does not differ significantly for various types of pulp. It is worth mentioning that the values of the volumetric mass transfer coefficient are of the same order of magnitude as those measured for oxygen transfer during batch cultivation in an airlift tower fermentor. ${ }^{24}$

The correlations (not shown in Fig. 8) between the wash water velocity (in $\mathrm{m} \mathrm{s}^{-1}$ ) and the volumetric mass transfer coefficient (in $\mathrm{s}^{-1}$ ) were derived in the form:

$k_{\mathrm{L}} a=54.0 u$ 
$k_{\mathrm{L}} a=63.8 u$

$k_{\mathrm{L}} a=49.0 u$

with a correlation coefficient of $0.953,0.983$, and 0.968 for the sulphite, kraft, and soda pulps, respectively.

Based on the specific surface area of the fibres (cf. Table 1) and the average effective flow porosity of the pulp bed ( $c f$. Fig. 2), it can be assumed that the specific area, $a$, contributes most substantially to the value of the volumetric mass transfer coefficient in the case of the short-fibred soda pulp, compared to the long-fibred pulps. Under the simplified assumption that the interfacial area in the unit volume of the pulp bed $a \approx(1-\varepsilon) a_{\mathrm{V}}$, the mass transfer coefficient, $k_{\mathrm{L}}$, varied within the limits of $(0.81-3.37) \times 10^{-8} \mathrm{~m} \mathrm{~s}^{-1}$ with the average of $1.65 \times 10^{-8} \mathrm{~m} \mathrm{~s}^{-1}$ for the shortfibred rapeseed soda pulp, while, for the longfibred spruce sulphite and kraft pulps, it ranged within the limits of (3.97-12.1) $\times 10^{-8} \mathrm{~m} \mathrm{~s}^{-1}$ and of $(5.05-23.2) \times 10^{-8} \mathrm{~m} \mathrm{~s}^{-1}$ with the average of 7.68 $\times 10^{-8} \mathrm{~m} \mathrm{~s}^{-1}$ and of $11.4 \times 10^{-8} \mathrm{~m} \mathrm{~s}^{-1}$, respectively. When comparing the values of the mass transfer coefficient, $k_{\mathrm{L}}$, it should be taken into account that the specific surface of fibres, $a_{\mathrm{V}}$, was determined for the pulp suspension in water and it may thus differ from the values for the pulp suspension in the black or red liquors.

The intensity of the solute transfer by leaching corresponds satisfactorily to the relationship between the mean residence time of the solute and space time. The mean residence time of the solute, alkali lignin and/or lignosulphonates, $t_{\mathrm{m}}$, is defined as:

$t_{\mathrm{m}}=\int_{t=0}^{t \rightarrow \infty} \frac{\rho_{\mathrm{e}}}{\rho_{0}} \mathrm{~d} t$

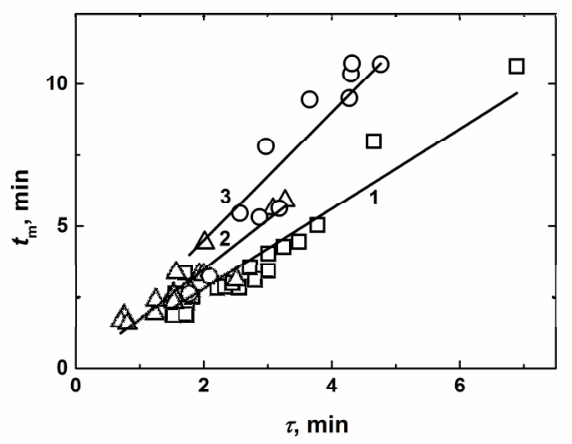

Figure 9: Dependence of mean residence time on space time for sulphite $(\square)$, kraft $(\triangle)$, and soda $(\bigcirc)$ pulps; solid line: 1 Eq. (25), 2 Eq. (26), 3 Eq. (27) and it characterises the residence time of the solute in the pulp bed. In contrast to this, the space time, $\tau$, defined as:

$\tau=\frac{h \mathcal{\varepsilon}}{u}$

characterises the holding time of the wash liquid in the pulp bed. ${ }^{12}$ It can be assumed that the more the leaching of solute affects the pulp washing, the more the mean residence time of solute will be greater than the space time because leaching is very slow process.

The mean residence time was plotted against the space time in Figure 9. With respect to leaching accompanying displacement, the mean residence time is always longer than the space time for pulp fibre beds, in agreement with the previous results. ${ }^{12}$

The correlation between both time parameters can be expressed as follows:

$t_{\mathrm{m}}=1.40 \tau$
$t_{\mathrm{m}}=1.74 \tau$
$t_{\mathrm{m}}=2.25 \tau$

with correlation coefficients of $0.956,0.920$, and 0.932 for sulphite, kraft, and soda pulps, respectively.

The lowest values of the mass transfer coefficient measured for the soda rapeseed pulp correspond satisfactorily to the relation between the mean residence time and space time given by Equation (27), while, for sulphite and kraft pulps, the coefficient of proportionality in Equations (25) and (26) is smaller comparing to Equation (27). The lowest coefficient proportionality between the mean residence time and space time (Eq. (25)) was obtained for the sulphite pulp with respect to the largest effective flow porosity of the pulp fibre bed (cf. Fig. 2).

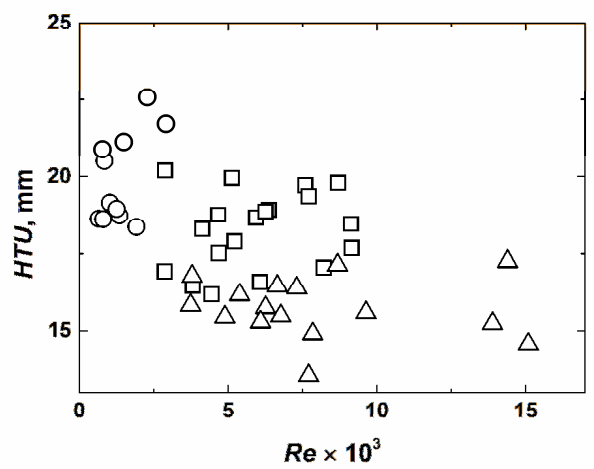

Figure 10: Influence of the Reynolds number on height of a transfer unit for sulphite $(\square), \operatorname{kraft}(\triangle)$, and soda (○) pulps 
Moreover, the relatively greater leaching intensity in the unit volume of the pulp bed expressed by $k_{\mathrm{L}} a$ for kraft pulp is associated with the lower height of a transfer unit, as follows from Figure 10, where the height of a transfer unit defined by Equation (15) is plotted against the Reynolds number of wash liquid flowing through the inter-fibre voids of the pulp bed. The average height of a transfer unit was found to be 18.3, 15.7, and $19.9 \mathrm{~mm}$ for sulphite, kraft, and soda pulps, respectively. In addition, the values of the Reynolds number $\left(R e<1.5 \times 10^{-2}\right)$ confirm unambiguously the laminar flow regime of the wash water flowing through the pulp fibre bed.

\section{CONCLUSION}

A packed bed of pulp fibres is a very tangled system consisting of randomly oriented, porous, compressible particles of different sizes. The results of displacement washing experiments carried out with three types of pulp differing in kappa number revealed the following conclusions.

(i) Although the consistency of the shortfibred soda rapeseed pulp bed was lower than that of the long-fibred spruce sulphite and kraft pulps, the effective flow porosity, equivalent pore diameter, and wash water permeability were considerably smaller, while the specific bed resistance was substantially greater for the rapeseed pulp in comparison with long-fibred spruce pulps. Due to the relatively high hydraulic resistance, the soda rapeseed pulp should be washed at a lower consistency than usual for long-fibred pulps.

(ii) The different size of fibres and their spatial orientation in the bed substantially affect the flow of the wash liquid through the bed and thus the course of lignin displacement. Hence, the bed efficiency is then unambiguously influenced by the Péclet number. Lower values of the Péclet number for the short-fibred rapeseed pulp result in lower washing efficiency. On the other hand, for long-fibred spruce pulps, the displacement process is accompanied by greater values of the Péclet number when the washing efficiency of the sulphite pulp was slightly higher than that of the kraft pulp, probably, due to greater effective flow porosity of the pulp bed.

(iii) The leaching process that follows displacement was characterised by the volumetric mass transfer coefficient, which increased linearly with increasing the superficial wash liquid velocity. The specific interfacial area based on the unit pulp bed volume contributes more to the mass transfer in the case of the rapeseed pulp, compared to the long-fibred spruce pulps. The fact that leaching contributes substantially to the washing process of rapeseed pulp is also confirmed by the longer mean lignin residence time in the bed, compared to space time.

ACKNOWLEDGEMENTS: This work was supported by the Ministry of Education, Youth, and Sports of the Czech Republic under the research project SGS_2019_005.

\section{SYMBOLS}

A cross-sectional area of pulp bed, $\mathrm{m}^{2}$

$a_{\mathrm{m}} \quad$ specific surface of pulp fibres based on fibre mass, $\mathrm{m}^{2} \mathrm{~kg}^{-1}$

$a_{\mathrm{V}} \quad$ specific surface of pulp fibres based on fibre volume, $\mathrm{m}^{-1}$

$B \quad$ permeability, $\mathrm{m}^{2}$

$D \quad$ axial dispersion coefficient, $\mathrm{m}^{2} \mathrm{~s}^{-1}$

$d_{\text {eq }} \quad$ equivalent pore diameter, $\mathrm{m}$

$E$ bed efficiency defined by Eq. (8), dimensionless

$E_{\mathrm{RW}=1} \quad$ bed efficiency at $R W=1$ defined by Eq. (9), dimensionless

$F C$ fibre coarseness, $\mathrm{mg} \mathrm{m}^{-1}$

$H \quad$ vertical distance from top of bed, $\mathrm{m}$

$h \quad$ bed thickness, $\mathrm{m}$

$k_{\mathrm{L}} a \quad$ volumetric mass transfer coefficient, $\mathrm{s}^{-1}$

HTU height of a transfer unit defined by Eq.

(15), m

$K \quad$ Kozeny constant in Eqs. (3) and (4), dimensionless

$L_{\mathrm{D}} \quad$ dispersion length defined by Eq. (18), dimensionless

$L_{0} \quad$ mass of liquor in pulp bed at $R W=0, \mathrm{~kg}$

$l_{\mathrm{A}} \quad$ arithmetic average fibre length, $\mathrm{mm}$

$l_{\mathrm{W}} \quad$ weighted average fibre length, $\mathrm{mm}$

NTU number of transfer units

$\Delta P \quad$ pressure drop, $\mathrm{Pa}$

$P e \quad$ Péclet number based on the thickness of the bed and defined by Eq. (16), dimensionless

$R \quad$ hydraulic resistance of pulp bed defined by Eq. (2), Pa s m ${ }^{-1}$

Re Reynolds number $\left(=4 u \rho_{\mathrm{WL}} /\left(a_{\mathrm{V}}(1-\varepsilon)\right.\right.$ $\mu$ ), dimensionless

$R W \quad$ wash liquor ratio, dimensionless

$R W_{\varepsilon} \quad$ wash liquor ratio defined by Eq. (13), dimensionless

$R W_{\infty} \quad$ wash liquor ratio at $R W \rightarrow \infty$, dimensionless 


\section{FRANTIŠEK POTU゚ČEK}

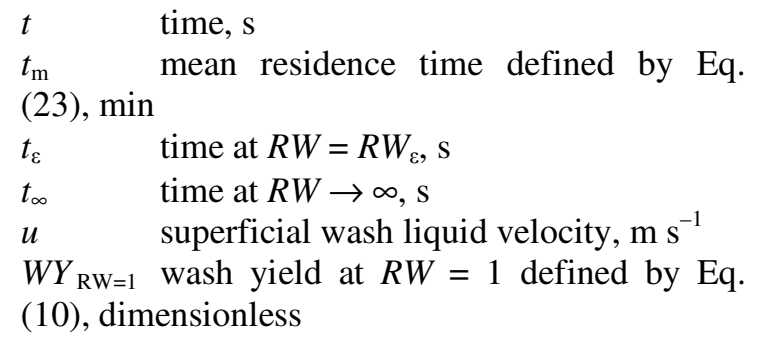

\section{Greek letters}

$\alpha \quad$ average specific bed resistance defined by Eq. (4), $\mathrm{m} \mathrm{kg}^{-1}$

$\varepsilon \quad$ average effective flow porosity of packed bed

$\mu \quad$ liquid viscosity, Pa s

$\rho$ density of black, red, and soda liquors in Table 2, $\mathrm{kg} \mathrm{m}^{-3}$

$\rho \quad$ local solute concentration within pulp bed, $\mathrm{kg} \mathrm{m}^{-3}$

$\rho_{\text {avg }} \quad$ average solute concentration within pulp bed defined by Eq. (7), $\mathrm{kg} \mathrm{m}^{-3}$

$\rho_{\mathrm{e}} \quad$ exit solute concentration in outlet stream of liquor, $\mathrm{kg} \mathrm{m}^{-3}$

$\rho_{\mathrm{F}} \quad$ consistency of pulp, $\mathrm{kg} \mathrm{m}^{-3}$

$\rho_{\mathrm{i}} \quad$ solute concentration in wash liquid, $\mathrm{kg} \mathrm{m}^{-3}$

$\rho_{\mathrm{WL}} \quad$ density of wash liquid in Eq. (13), $\mathrm{kg} \mathrm{m}^{-3}$

$\rho_{0} \quad$ initial solute concentration in bed at $R W=0$,

$\mathrm{kg} \mathrm{m}^{-3}$

$\sigma \quad$ surface tension, $\mathrm{N} \mathrm{m}^{-1}$

$\tau \quad$ space time defined by Eq. (24), $\min$

\section{REFERENCES}

1 R. H. Crotogino, N. A. Poirier and D. T. Trinh, $\begin{array}{llll}\text { Tappi J., } & \text { 70, } & 95 & \text { (1987), }\end{array}$ https://www.tappi.org/Search/?srchtext=publisher

2 E. O. Ericsson and D. M. Moody, Tappi J., 66, 43 (1983), https://www.tappi.org/Search/?srchtext=publisher

3 R. J. Nunge and W. N. Gill, Ind. Eng. Chem., 61, 33 (1969), https://www.journals.elsevier.com/journalof-industrial-and-engineering-chemistry

4 F. Potůček, Cellulose Chem. Technol., 37, 391 (2003), http://www.cellulosechemtechnol.ro/

5 F. Potůček, Cellulose Chem. Technol., 37, 141 (2003), http://www.cellulosechemtechnol.ro/

6 S. Arora and F. Potůček, Cellulose Chem. Technol., 43, $307 \quad$ (2009), http://www.cellulosechemtechnol.ro/pdf/CCT7-82009/p.307-315.pdf

7 S. Arora and F. Potůček, Indian J. Chem. Technol., 19, $140 \quad$ (2012), http://nopr.niscair.res.in/handle/123456789/55

8 F. Potůček and M. Rahman, Cellulose Chem. Technol., $\quad 52, \quad 393 \quad$ (2018), http://www.cellulosechemtechnol.ro/pdf/CCT56(2018)/p.393-401.pdf

9 F. Potůček and K. Hájková, Chem. Pap., 69, 1067 (2015), https://doi.org/10.1515/chempap-2015-0106
10 W. L. Ingmanson, Chem. Eng. Prog., 49, 577 (1953),

https://www.scimagojr.com/journalsearch.php?q=Ame rican Institute of Chemical Engineers\&tip=pub

11 P. F. Lee, Tappi J., 62, 75 (1979), https://www.tappi.org/Search/?srchtext=publisher

12 F. Potůček, Collect. Czech. Chem. Commun., 62, 626 (1997), https://doi.org/10.1135/cccc19970626

13 F. Potůček and M. Marhanová, Sci. Papers Univ. Pardubice, Ser. A, 4, 223 (1998), https://fcht.upce.cz/fcht/veda-

vyzkum/casopisy/scientific.html

${ }_{14}$ R. B. Bird, W. E. Steward and E. N. Lightfoot, "Transport Phenomena", Academia, Praha, 1968 (in Czech).

$15 \mathrm{P} . \mathrm{Xu}$ and B. Yu, Adv. Water Resour., 31, 74 (2008), https://www.journals.elsevier.com/advancesin-water-resources

16 J. D. Lindsay, Tappi J., 77, 225 (1994), https://www.tappi.org/Search/?srchtext=publisher

17 A. J. M. Herwijn, E. J. L. Heij, J. J. Ijzermans, W. J. Coumans and P. J. A. M. Kerkhof, Ind. Eng. Chem. Res., 34, $1310 \quad$ (1995), https://pubs.acs.org/journal/iecred

18 W. L. McCabe, J. C. Smith and P. Harriott, "Unit Operations of Chemical Engineering", $6^{\text {th }}$ ed., McGraw-Hill, Boston, 2001.

19 H. T. Cullinan, Appita J., 44, 91 (1991), https://appita.com/publication-resources/appitamagazine-appita-peer-reviewed-journal

${ }^{20}$ P. F. Lee, Tappi J., 67, 100 (1984), https://www.tappi.org/Search/?srchtext=publisher

21 S. A. Rydholm, "Pulping Processes", J. Wiley \& Sons, New York, 1965.

22 F. Potůček, Pap. Celul., 56, 8 (2001), http://www.svettisku.cz/buxus/generate_page.php?pag e_id=6869\&buxus_svettisku=

${ }^{23}$ E. Mauret and M. Renaud, Appita J., 55, 123 (2002), https://appita.com/publicationresources/appita-magazine-appita-peer-reviewedjournal 24 F. Potůček, Collect. Czech. Chem. Commun., 54, 3213 (1989), https://doi.org/10.1135/cccc19893213 